physicians concerned about the country's readiness if a second pandemic (H1N1) 2009 wave hits in the fall.

"I don't think that everybody realizes that the pandemic stores, the emergency store of ventilators that a lot of people are depending upon in case of emergency, simply aren't advanced enough to take care of these patients," says Kumar.

Ventilators made more than 15 years ago and those routinely used in emergency rooms aren't advanced enough for this type of therapy, he adds. However, older ventilators may be useful for the less severely injured.

In a written response to CMAJ questions, the Public Health Agency of Canada (PHAC) confirmed that of the additional 370 ventilators it is trying to purchase as part of its National Emergency Stockpile System, none are oscillating ventilators. PHAC does not have a stockpile of heart-lung bypass machines.

Nurses and respiratory technologists will be as critical if Canadian hospitals see even 3.5 times more cases of pandemic (H1N1) 2009 patients with lung injuries in a second wave - and that is a conservative estimate, says Dr. Allison McGeer, director of infection control at Toronto's Mount Sinai Hospital. Like Kumar and Fowler, she is concerned that ICUs may become the choke point in the health care system come fall.

Unlike ICUs in the United States, which routinely keep some beds empty and ventilators free, Canadian units normally run at $90 \%-95 \%$ full sometimes more, with patients waiting in emergency before being admitted. "It's very efficient from a systems point of view, but it means we have no surge capacity in our ICUs in Canada," says McGeer. Even so, "I am less worried about the ventilator supplies than I am about the staff resources to care for them," she adds.

Hospitals should also be stockpiling sedatives, paralytics and antibiotics, because the ventilated patients with pandemic (H1N1) 2009 often require "massive" sedation.

Administrators should also be making plans to designate staff to make tough triage choices, Kumar says. "The idea of, how you triage 2 young people to a single ventilator — that's a very difficult issue."

Fowler is also worried that Canadian hospitals will have to limit resources to people who are very sick because of inadequate capacity. "That's a position we haven't found ourselves in throughout the history of medicare in Canada."

With each province and region developing its own pandemic plan, the Canadian Critical Care Society is concerned that "from a national perspective, there's no coordinated effort to help with resource utilization and sharing that sort of resource planning," says Dr. John Granton, a Toronto ICU physician and the Society's president.

Pandemic planning has largely been devoted to securing a vaccine and rolling out immunization, but federal oversight is needed to ensure provincial licensing requirements are waived and malpractice insurance is extended so that, if necessary, health care professionals and medical equipment can be shared between jurisdictions, Granton says. — Laura Eggertson, Ottawa, Ont.

DOI:10.1503/cmaj.109-3005

\title{
Medical literature, made to order
}

$\mathrm{M}$ any publishers of scientific journals have divisions that produce customized publications for drug companies, and some experts in medical publishing standards say it's becoming increasingly difficult to distinguish science from marketing.

"The whole area of the pharmaceutical relationship with journals in this sort of gray literature is not really well spelled out, mainly because it's often not clear where editorial responsibility lies," says Dr. Virginia Barbour, a PLoS Medicine editor and secretary of the Committee on Publication Ethics, a United Kingdom-based charitable organization whose membership is comprised primarily of the editors-in-chief of scientific journals.

The 6 fake medical journals that recently brought scientific publisher Elsevier heaps of negative publicity were released under the company's communications division, Excerpta Medica Communications. The division partners with clients "in the pharmaceutical and biotech industries to educate the global health community," according to its website (www.excerptamedica.com).

"The biggest issue here was the lack of disclosure," says Barbour.

One case study posted on the website describes the division's efforts to promote a client's cardiovascular product in a crowded market. It did this by producing a company-sponsored journal (the word "journal" was replaced on the website by "publication" sometime after $C M A J$ spoke with representatives from Excerpta Medica Communications in mid-July) to "establish this client as one of the industry's authorities on cardiovascular disease."

Elsevier has admitted that the pharmaceutical industry-funded "Aus-

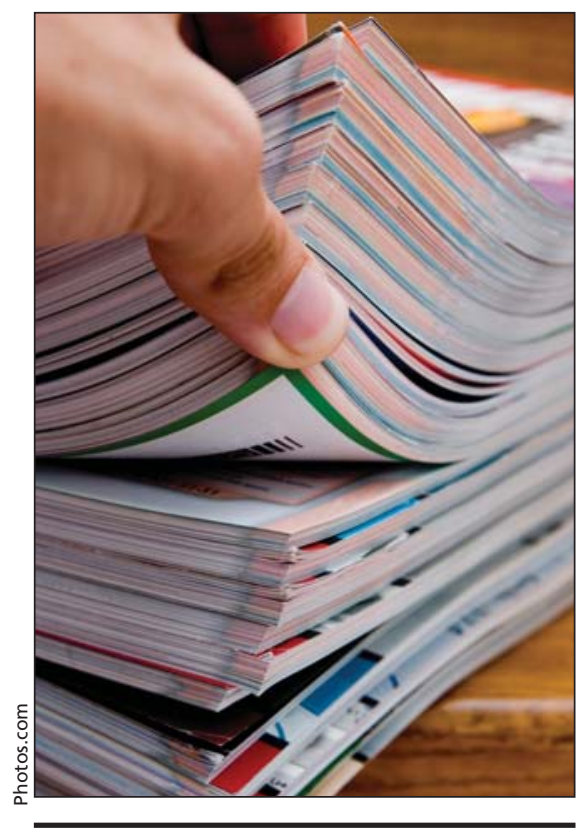

Critics of the pharmaceutical industry's influence on academic publishing say it is becoming more difficult to tell if the content of medical journals is science or marketing. 
tralasian Journal of..." series of publications, released in Australia between 2000 and 2005 under the Excerpta Medica imprint, lacked proper disclosure and shouldn't have had the world "journal" in their titles. The company has since conducted an internal audit of its publishing practices.

Edward Roos, managing director of Excerpta Medica Communications, says materials published by his division are not intended to mimic peerreviewed medical journals and don't look like medical journals (they are glossier and have more visuals). They don't carry original scientific data, aren't peer reviewed and contain the names of sponsors. On the other hand, he adds, the publications also aren't designed to look like traditional promotional material. "The idea of a customized journal is that you develop it in such a way that you have a reputable editorial board. You have content which is screened by them and agreed to by them. If it becomes too promotional, you lose the impact of the journal, and you might as well not do it."

Elsevier has plenty of company in the sponsored-publication business. The academic publisher Springer has a division called Springer Healthcare Communications, which produces customized books and journals. Springer Healthcare Communications' website (www.springerhealthcare.com/customised_journals.asp) states that it has "access to a broad range of Medline indexed peer-reviewed journals through our parent company Springer and is therefore in an ideal position to work with you to supply journals customised to your requirements." One journal published under this imprint is Advances in Therapy.

The academic publisher John Wiley and Sons, Inc. has a communications division called Wiley Interface, which will also print "custom journal and book publications," according to its website (ca.wiley.com/WileyCDA/Section/id-301748.html). Journal titles bearing the Wiley Interface imprint include Future Prescriber, Prescriber, Trends in Urology, Gynaecology and Sexual Health, Practical Diabetes International and Progress in Neurology and Psychiatry. The company refers to these titles, available only in the UK, as "medical controlled circulation titles," which can "support a whole range of advertising and sponsored medical communication and education activities" (www.escriber.com).

Tim Dean, medical journals publisher at Wiley-Blackwell, says these publications are independent of commercial interests, peer reviewed, and funded by display advertising and subscription revenue. "We don't publish any custom journals for the industry. Although the journals are not sponsored we do publish supplements to the journals that can be sponsored. The sponsor of a supplement is clearly indicated on the front cover," Dean writes in an email. "Sponsored supplements are designed not to be mistaken for the journal itself."

Several Wiley Interface titles were obtained (after being contacted by $C M A J$ ) by Alastair Matheson, a United Kingdom academic who has worked extensively as an analyst, writer and consultant in the pharmaceutical and biomedical industries. He says that Practical Diabetes International, which states it is peer reviewed (and contains conflict-of-interest statements from authors), appears to mostly contain reviews, digests and news pieces, and reads like a magazine.

Prescriber and Future Prescriber don't claim to be peer reviewed and don't contain conflict-of-interest statements from authors; nor do they provide information about the origin of articles (which consist of reviews, digests and news), says Matheson, who recently published an article analysing the role the pharmaceutical and medical-device industries play in producing scientific and medical knowledge (BioSocieties 2008;3[4]:355-82).

"If one were to coin a phrase for these journals, we might call them 'soft portals' — conduits through which potential prescribers can be reached, which, while lacking the rigour and credibility of high-end journals, are approachable, user-friendly and easy on the brain for the busy physician," Matheson writes in an email to CMAJ.

One potential way to clarify between high-end journals and lesscredible publications, suggests Matheson, would be to create an "Interna- tional Standard of Integrity in Science." Journals that meet the standard could then carry a logo by which doctors could judge their credibility. "If this idea took off, it would place great pressure on journals, pharma and publishers to clean up their act," writes Matheson. "To be eligible for the standard, there would have to be full explication of the origination and sponsorship of the articles the journal published."

Some critics of the influence that drug companies have on medical publishing say more drastic measures are needed to improve the integrity of scientific literature. Arthur Schafer, director of the Centre for Professional and Applied Ethics at the University of Manitoba in Winnipeg, says that even articles in high-end journals are often ghostwritten by "paid hacks" to promote drugs. The only solution, he suggests, is for medical journals to stop publishing industry-funded research, which tends to far too often yield results favourable to drug companies.

"Then we would have honest science," says Schafer. "We don't have science with integrity at the moment. The system guarantees that science will 
more and more resemble marketing."

Governments could also help, by passing regulations that would make it illegal for companies to be involved in both scientific research and marketing. This would be a radical move, altering the way drug companies work, but it is feasible, says Sergio Sismondo, a philosophy professor at Queen's University in Kingston, Ontario.

"There isn't a clean distinction between something that is purely PR and something that serves PR purposes and something that is a normal academic medical journal that can be used for PR," says Sismondo. "There are no rules whatsoever about this. Anybody can publish a journal."

Dr. Joseph Ross, an assistant professor with the Mount Sinai School of Medicine, has also written about medical ghostwriting (JAMA 2008;299[15]: 1800-12). Ross says there is a need for clearer divisions in academic publishing between unbiased scientific content and information originated from drug advertisers. "It's all intertwined and hard to differentiate from the outside," he says.

Prominent journals also have a role to play in cleaning up medical literature, says Dr. David Healy, a psychiatrist at the University of Cardiff in Wales, United Kingdom, and a critic of the drug industry's influence on physicians' drug prescribing habits. Healy says that many "kosher journals" have become very dependent on pharmaceutical advertising and supplements. Some doctors deride supplements as "throw-aways" and claim they have no influence, but Healy says there is a cumulative effect to flooding doctors' offices with supplements: the benefits of new drugs become widely disseminated while the risks remain largely unknown.

"The fact that there are a bunch of symposium supplements that say drugs are good for X, Y and Z and don't have hazards $\mathrm{A}, \mathrm{B}$ and $\mathrm{C}$, and that these can be readily produced, is good for the finances of journals but bad for medicine." - Roger Collier, CMAJ

DOI:10.1503/cmaj.091334

\section{More news at cmaj.ca}

Listeriosis probe: Federal investigator says the 2008 deadly listeriosis outbreak was largely caused by inadequate reporting requirements, insufficient coordination of government departments and a failure to properly communicate to Canadians how to minimize the risk of becoming sick. - Christopher Mason, Ottawa, Ont.

Swine flu spread: Longstanding federal strategies and polices have exacerbated the rapid spread of pandemic (H1N1) 2009 influenza in remote First Nations communities, public health officials and aboriginal health experts charge. - Paul Webster, Toronto, Ont.

Reactors: Canadian life sciences company MDS Nordion wants the federal government to bring international experts to Chalk River, Ontario, to determine what it

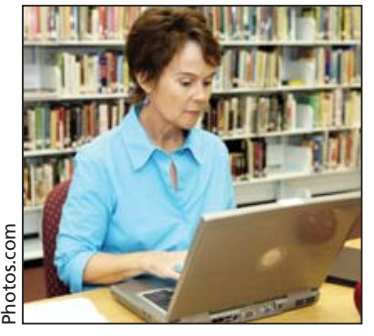
would take to fix 2 discredited nuclear reactors. Roger Collier, CMAJ

Journals: Librarians say the distinction between legitimate medical journals and marketing rags are often difficult to spot. - Roger Collier, CMAJ
Whirlwind: The Canadian Medical Association's new president, Dr. Anne Doig, has a firm moral compass. - Wayne Kondro, CMAJ

Coping with drug costs: Governments are exploring mechanisms to lower annual tabs for prescription drugs. - Ann Silversides, CMAJ

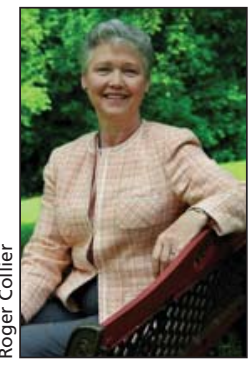

Ishould: Medical decision-making application available on social networking website.- Elizabeth Wilcox, Toronto, Ont.

Positioning: A mobile intra-operative imaging system is being put to good use in a Halifax, Nova Scotia, hospital. — Donalee Moulton, Halifax, N.S.

Mysteries: A Hamilton, Ontario doctor contemplates the myriad facets of conducting research. - Chelsea Maedler-Kron, Hamilton, Ont.

Differing indications: An Ottawa physician says there have been significant advances in AIDS treatment in Ethiopia. Cherinet Seid, MD, Ottawa, Ont.

DOI:10.1503/cmaj.109-3002 